\title{
Formación profesional por competencias en terapia física. Aplicación real en la Universidad Peruana de Ciencias Aplicadas
}

\author{
Giancarlo Becerra-Bravo, Flor Zuzunaga-Infantes
}

En la actualidad, numerosas escuelas de terapia física en Perú proponen formar profesionales con el diseño curricular por competencias, incluyendo en su agenda anual sesiones de capacitación y guía al docente que dictará durante el semestre.

Estas sesiones, además de tediosas y con poca estructuración, muchas veces guían inadecuadamente al docente en esta manera de enseñanza, ya que ni la misma institución tiene claras las competencias con las cuales quiere formar a sus profesionales.

De esta manera, en base a diversos artículos publicados en Educación Médica [1-3], exponemos nuestra experiencia en la carrera de terapia física de la Facultad de Ciencias de la Salud de la Universidad Peruana de Ciencias Aplicadas, en Lima.

Desde hace ya dos años, como parte de su agenda anual, la carrera de terapia física convoca dos reuniones previas a los docentes que dictarán durante ambos semestres; dentro de ellas exponen los pilares de la carrera, como las competencias generales de la universidad y la visión, misión y objetivos que se plantea la institución docente para lograr la excelencia en la formación universitaria. Luego se exponen las principales competencias diseñadas para el licenciado en terapia física y los respectivos criterios de cada competencia, que se diseñan estratégicamente para que el licenciado sea un profesional competente en el ámbito internacional. De esta manera, el docente comienza el proceso de creación de su curso guiado por las competencias sugeridas, diseñando rubricas específicas y adaptándolas al sistema vigesimal utilizado en Perú, ya que para evaluar las competencias exige disponer de instrumentos de cuantificación estandarizados y de un referente claro de lo que es un profesional competente [1].

Para lograr los objetivos planteados por la escuela al docente, se le asignan diez horas de capacita- ción obligatoria en las cuales se le inserta en el modelo educativo; de éstas, cuatro horas se dedican al modelo educativo, y seis, al diseño por competencias de sus respectivos cursos. Así, el docente se plantea desde una primera instancia cuál será el logro final de su curso y qué competencias adquirirá el alumno en sus unidades para completar este logro. Al obtener estos datos cuantitativos y cualitativos de su curso se realiza una de las partes más importantes del modelo por competencias: la evaluación de éstas [3]. Durante este proceso de la reunión surge, como planteamiento principal a la evaluación realizada en el curso, la cuestión de cuál es el objetivo de la propia evaluación [3]; mediante esta pregunta, los docentes diseñan un programa bien estructurado dentro de sus syllabus para evaluar de manera específica a los alumnos. Para que el logro/ competencia sea realmente aprendido por el alumno, el docente, además del diseño de su curso, también realiza un diseño específico y estructurado de su material de clase, como guías de práctica, metodología aplicada en cada clase, videos, casos, etc.

En conclusión, debemos destacar que tanto los docentes como las autoridades de la carrera de terapia física de la Universidad Peruana de Ciencias Aplicadas se comprometen exigentemente a diseñar una real formación profesional por competencias, que se reflejará en la calidad de sus próximos licenciados.

\footnotetext{
Bibliografía

1. Palés-Argullós J, Nolla-Domenjó M, Oriol-Bosch A, Gual A. Proceso de Bolonia (I): educación orientada a competencias. Educ Med 2010; 13: 127-35.

2. Oriol-Bosch A. El reto de Bolonia: la evaluación de las competencias. Educ Med 2010; 13: 123-5.

3. García-Seoane JJ. Objetivo cumplido: la evaluación de competencias en la Facultad de Medicina de la Universidad Complutense de Madrid. Educ Med 2008; 11 (Supl 1): S63-7.
}

Universidad Peruana de Ciencias Aplicadas. Lima, Perú.

Correspondencia: Lic. Flor Zuzunaga Infantes. Universidad Peruana de Ciencias Aplicadas. Avda. Primavera, 2390 Lima, Perú.

E-mail:

flor.zuzunaga@upc.edu.pe

(c) 2012 Educación Médica 